\title{
DESIGN RESEARCH OF TIANDITU (MAP WORLD)-BASED GEOGRAPHIC INFORMATION SYSTEM FOR TRAVELLING SERVICE
}

\author{
ZHANG Junhui ${ }^{\mathrm{a}}$ *, ZHANG Hongping ${ }^{\mathrm{a}}$, WANG Cong ${ }^{\mathrm{a}}$ \\ ${ }^{a}$ National Geomatics Center of China, Lianhuachixi Road, Haidian District, Beijing, 100830,China
}

\section{Commission}

KEY WORDS: TIANDITU, Geographic information, Travelling service system

\begin{abstract}
:
TIANDITU (Map World) is the public version of the National Platform for Common Geospatial Information Service, and the travelling channel is TIANDITU-based geographic information platform for travelling service. With the development of tourism, traditional ways for providing travelling information cannot meet the needs of travelers. As such, the travelling channel of TIANDITU focuses on providing travel information abundantly and precisely, which integrated the geographic information data of TIANDITU Version 2.0 and the authoritative information resources from China National Tourism Administration. Furthermore, spatial positioning, category and information query of various travelling information were offered for the public in the travelling channel. This research mainly involves three important parts: the system design, key technologies of the system design and application examples. Firstly, this paper introduced the design of TIANDITU-based geographic information system for travelling service, and the general and database design were described in detail. The designs for general, database and travelling service above should consider lots of factors which illustrated in the paper in order to guarantee the efficient service. The process of system construction, the content of geographic information for travelling and system functions of geographic information for travelling are also proposed via diagram in this part. Then several key technologies were discussed, including the travelling information integration for main node and among nodes, general architecture design and management system for travelling channel, web portals and system interface. From the perspective of main technologies, this part describes how TIANDITU travelling channel can realize various functions and reach the requirements from different users. Finally, three application examples about travelling information query were listed shortly. The functions and search results are shown clearly in this part. In all, TIANDITU-based geographic information system for travelling service aimed to integrate the travelling information resources from national, provincial and municipal levels, and finally realized to provide "one stop" travelling service for users in the end.
\end{abstract}

\section{INTRODUCTION}

As the vital strategic information resources, geographic information plays an significant role in government decision, industrial development and people's livelihood ${ }^{[1]}$. Recently, the demand for web geographic information services is growing from the public and all levels of government, which is authoritative and reliable. According to demand above, TIANDITU realized interconnection and collaborative service of geographic information resources from different levels (national, provincial and municipal level), which bases common geographic frame data of globalization, chooses web map and geographic information services as presentation pattern.

TIANDITU is the public version of National Platform for Common GeoSpatial Information Services, which runs in network environment, includes geoinformation data system, service system, and server cluster system. And it can provide geoinformation for users by web portals and second development interface ${ }^{[2]}$. So TIANDITU changes the way of offering off-line information services before, now surveying and mapping geographic information department have realized provide online information services since TIANDITU released $^{[3]}$.

In recent years, domestic researchers conduct amount of researches and practices on the application of TIANDITU,such as earthquake information release ${ }^{[4]}$, design and implementation of accessibility facilities map service system ${ }^{[5]}$ and etc. These researches, however, focus on functions of map operation, data collection and data query. TIANDITU travelling channel collects travelling geographic information and realized integrated management, and carry out the development and design of the channel. And the construction of travelling channel aims at achieving services integration of travelling information resources from national, provincial and municipal level, and finally providing travelling "one stop" service of geographic information for users.

\section{SYSTEM DESIGN}

With the development of tourism industry, traditional travelling websites cannot meet the needs for travelers. The travelling plan for routes, services and other information becomes increasingly important. Thus, a travelling information platform which include reliable travelling information, attractions information and travelling map information is necessary. To construct an efficient information platform is one of the goals for TIANDITU's travelling channel.

\subsection{General Design}

The progress of system construction consist of the steps for channel development design, travelling geographic information collection, travelling data processing and etc, and it describes the whole progress of system construction. The detailed steps of system construction described in Figure 1.

*Corresponding author. zhangjunhui@ngcc.cn 


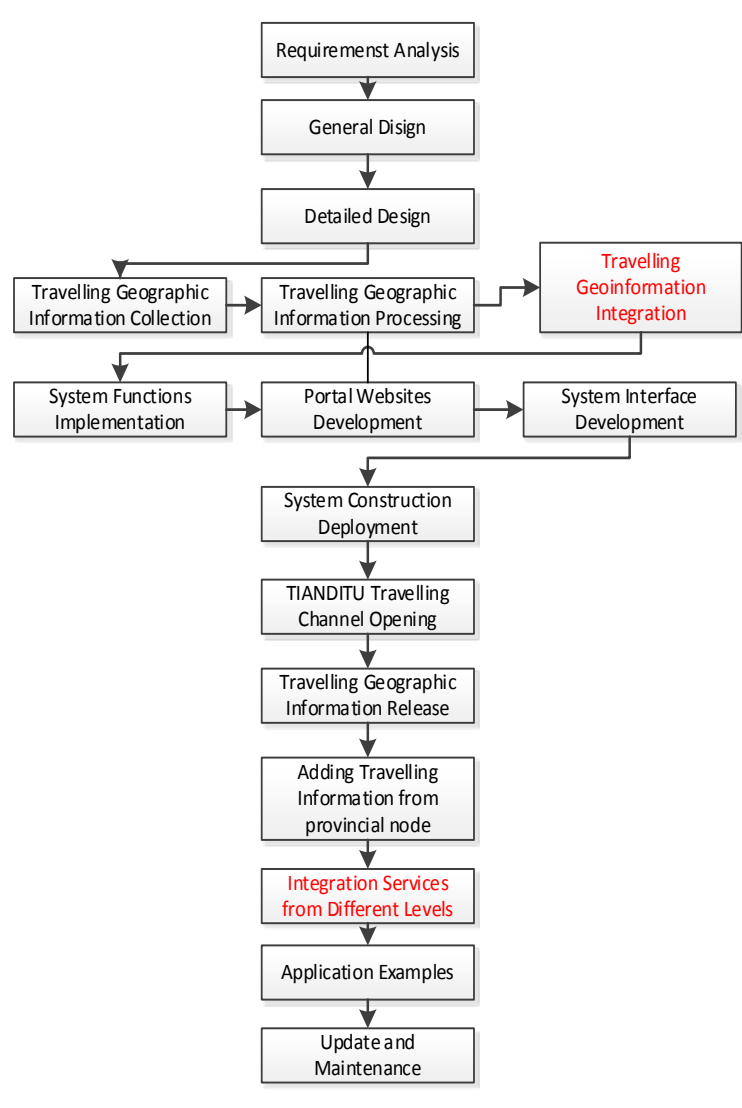

Figure 1: Flow Diagram of System Construction

\subsubsection{Travelling Geoinformation Integration}

Travelling geographic information integration belongs tourism informatization field. In China, tourism informatization begins in 1990s and makes significant progress during twenty years. Now the researches on tourism informatization center on tourism enterprise informatization, tourism e-business and tourism electronic government affairs ${ }^{[6]}$. And the tourism electronic government affairs is meaningful application in government ${ }^{[7]}$.

The widespread using of web and information technology lead to the rapid development of tourism ${ }^{[8]}$. Also, the web map used widely, and various map data is abundant in provincial and municipal scope. Tourist map, scenic area map, scenic terrain map, aerial image and satellite image are abundant. But the processing methods are not efficient and effective, and emphasizes are mussy. So the data above cannot meet the needs of data releasing of TIANDITU travelling thematic data.

Hence, TIANDITU travelling channel integrates different travelling geoinformation which is reliable and authoritative.

\subsubsection{Integration Services from Different Levels}

Integration Services emphasis on uniting atomic service and composite service which possess sole functions according to certain rules and standards, and generating a new service that owns complicate and strong functions ${ }^{[9]}$. This technology can integrate the information and function deployed in different locations $^{[10]}$. Though integration services introduced in lots of research, the definition, research content and technology system of spatial information integration service are not clear $^{[11,12,13]}$.

Spatial information service integration is in the SOA application environment ${ }^{[14]}$.The integration service of TIANDITU travelling channel is one of the spatial information service integration. It assembles existing map data, travelling thematic data and government information based on new logic, and finally realizes multi-services.

\subsection{Database Design}

Various kinds of travelling information can realize integration via position matching and code management. In order to highlight characteristic travelling services, the data content will be refined, classified, separated layers.

\subsubsection{Travelling geoinformation}

Travelling information content mainly included scenic spots, scenic area information, transportation information, hotel information, recreation information, shopping information, culture characteristic information and travelling characteristic information. And the details show in Figure 2. And the scenic spots and scenic area information is the importation information for service integration in TIANDITU main node ${ }^{[15]}$.

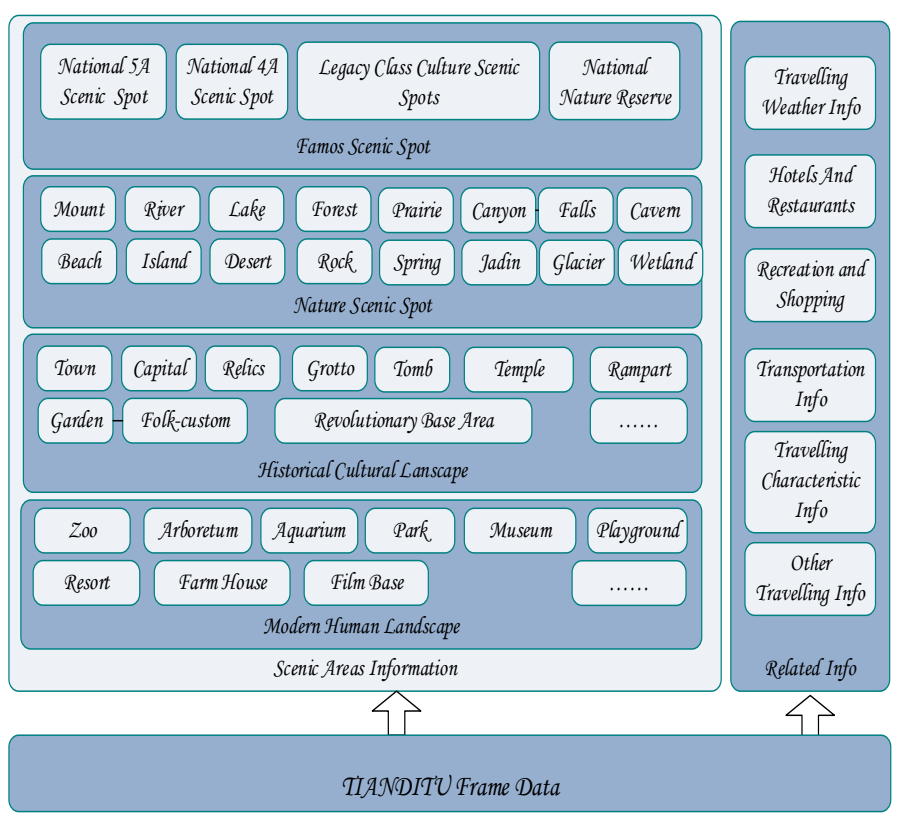

Figure 2: Geographic Information for Travelling

\subsubsection{Travelling data type information}

Data types of travelling information mainly include scenic spot, scenic area coordinate point information, pictures, videos, audios, scenic area introduction, scenic area remote sensing image, 3D model and etc. And some detailed address information is the foundation of spatialization display.

\subsection{Travelling Channel Design Base on TIANDITU}

TIANDITU travelling channel is the tourism geoinformation service platform based on TIANDITU Version 2.0. The channel has employed data from National Administration of Surveying, 
Mapping and Geoinformation, China National Tourism Administration, and TIANDITU Co., LTD.

The functions which developed based on the travelling channel design can be classified to the basic functions and extended functions. Firstly, the basic functions consist of travelling geoinformaion scan, travelling information query and retrieves, travelling map services, travelling routes selection and the travelling information spatial analysis, that are the foundation of the channel. Secondly, the extended functions further add some characteristic travelling services. The functions are formed by travelling scene simulation, traveling service customization, travelling information upload and release, which are characteristic for travelers.

\section{KEY TECHNOLOGIES OF SYSTEM DESIGN}

The system design involves several key technologies of system design which ensure the travelling channel works well. In the system design, the travelling geoinformation data integration and processing on main node or among nodes, the travelling channel general architecture design, the management system design, web portals and system interface effect important role in the channel.

\section{APPLICATION EXAMPLES}

The points introduced in this paper has practiced in TIANDITU web portal, the results shows that the methods are feasible and efficient. Travelling channel integrates the travelling resources from National Administration of Surveying, Mapping and Geoinformation, China National Tourism Administration, and TIANDITU Co., LTD. It collects information more than twenty thousand attractions, and combines with TIANDITU public map service platform, to provide attractions information services such as information query, spatial distribution display and detailed introduction. The travelling query results shows in Figure3.

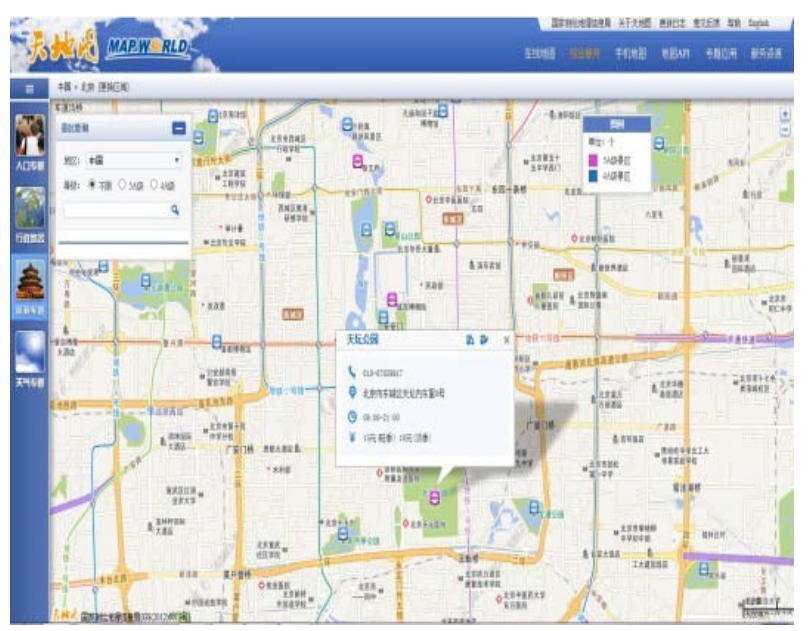

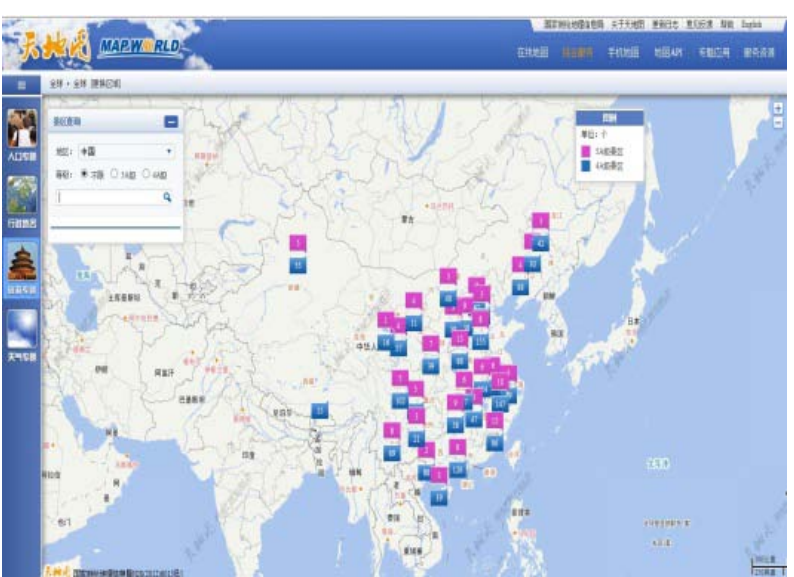

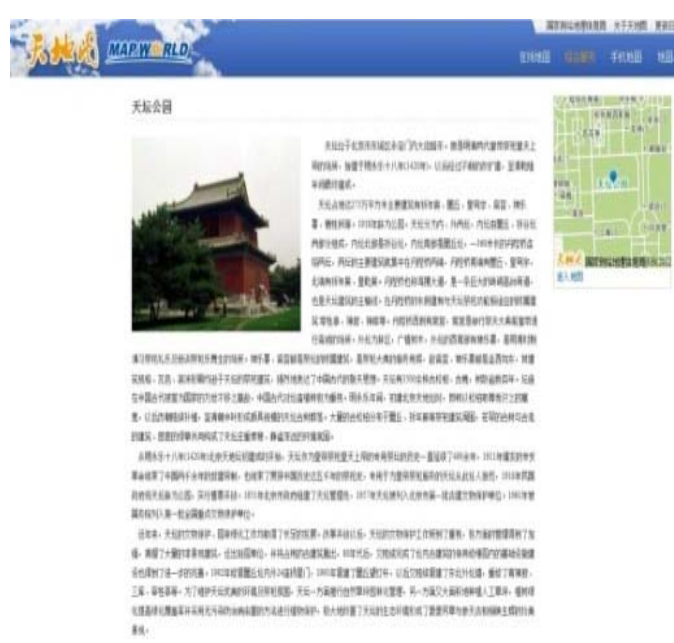

Figure 3: Search Results of TIANDITU for Travelling

\section{CONCLUSION}

TIANDITU-based geographic information system for travelling service has a positive effect on develop TIANDITU's service content, scopes and fields. And the functions and using rate also developed. Now it plays an important part in supporting tourism management, government decision making and public services. And the geoinformation resources in the tourism effects momentous role.

\section{Reference}

[1] GONG, Jianya. Foundation of Geographic information system[M]. BeiJing: Science Press, 2003.

[2] HUANG, Wei, JANG, Jie, WANG, Qian. Geo-spatial Framework Data System in Platform of Geographic Information Service[J]. Geomatics World, 2011, 08(4): 20-23.

[3] DONG, Xing-hong, HE, Zhao-xia, DUAN, Feng. Application of Map World in the Seismological Field[J]. Jounal of Seimological Research, 2011, 34(4): 552-557.

[4] Qui, Haijiang. The application of map world in earthquake release[J]. Microcomputer \& Its Applications, 2012, 31(21): 71-72.

[5] YE, Rongqing. Design and Implementation of Barrier-free Facilities Map Service System Based on Map World - Fujian Part[J]. Standardization of Surveying and Mapping, Xi'an, 2013, 29(1): 31-33.

[6] FU, Xisan. Literature Review Summary of Tourism Informatization[J]. Commercial Times, 2009, (2): 95-96.

[7] LI, Tian, TAO, Yefen, DI, Minghui. Development Strategy Study of Tourism Informatization[J]. China Collecitve 
Economy, 2009, (25): 34-37.

[8] Wang, Songjiao, Song, Xiaowei. Tourism Informatization Deciphering[J]. China Computer Users, 2008, (29): 16-17.

[9] Nurmamat, Mrkim. Research and Application of Spatial Information Servuces Aggregation in The Standard Farmland Management[D]. Zhejiang: Zhe Jiang Unniversity, 2013.

[10] FENG, Rong-xiang, XIE, Zhong, LUO, Xian-gang. A service aggregative model of distributed spatial data[J]. Science of Surveying and Mapping, 2013, 38(1): 44-46.

[11] LIU, Shulei. Research on the Composition Techniques of Geo-spatial Web Services Based On Workflow[D]. Changsha: Graduate School of National University of Defense Technology, 2006.

[12] Wang, Fangxiong. Research on Automic Services-based Interoperability of Grid Geospatial Information Service[D]. Wuhan: Wuhan University, 2005.

[13] Wu, Huanping. Key technology research of Geographic information Web Services[D]. Beijing: Beijing University, 2005.

[14] Wang, Qiang. Research on Key Technologies of Spatial Information Services Aggregation[D]. Zhengzhou: PLA Information Engineering University, 2010.

[15] RUAN, Jian, LIU, Bo, LI, Da-jun, ZOU, Shi-lin. Discussion on the application of small digital photogrammetry in the cadastral survey[J]. Science of Surveying and Mapping, 2009, 34(6): 298-299. 